\title{
Student and Faculty Perceptions of the Quality of Online Learning Experiences
}

\author{
Michael E. Ward, Gary Peters, and Kyna Shelley \\ The University of Southern Mississippi
}

\begin{abstract}
Some faculty members are reluctant to offer online courses because of significant concerns relative to the impact of such formats on the quality of instruction, learning, and participant interaction. Faculty members from The University of Southern Mississippi implemented synchronous interactive online instruction (SIOI) in the spring of 2007. This article explores the rationale for use of the particular technology, faculty conclusions regarding implementation of the technology, and the impact of the technology on instruction and learning. Comparisons by students of the quality of the learning experience in this environment with the quality of learning in face-to-face and asynchronous online learning environments were also analyzed.

The study finds that instructors and students view SIOI favourably. The mean student ratings for the dimensions of instructional quality were the same for SIOI and face-to-face course formats in all but one dimension, but mean ratings for SIOI and face-to-face formats were consistently higher than those for asynchronous online instruction. The single exception was for the dimension, ease of access to the course; the SIOI and asynchronous online formats were rated higher than the face-to-face format in this quality dimension. These findings suggest that it is possible to achieve levels of effectiveness in an online instructional format similar to those that are realized in face-to-face delivery. However, there is slight, though not statistically significant, evidence of concern about the quality of student collaboration in SIOI-enabled courses. Thus, instructors will need to capitalize on available mechanisms for interaction and collaboration.
\end{abstract}

Keywords: Internet in education; discussion in education; web-based instruction; online courses; instructional effectiveness in higher education 
Most universities now offer some coursework online and some have converted programs of study in order to make them entirely available online. Approximately 4.6 million college students in the USA took at least one online course during the fall semester of 2008; this number doubled the 2.3 million students who took online courses in the fall of 2004 (Allen \& Seaman, 2010; Allen \& Seaman, 2006). In 2009, 73\% of higher education institutions reported growth in demand for online courses and programs (Allen \& Seaman, 2010). Most chief academic officers in universities (58\%) perceive that online learning is critical to the long-term instructional strategies of their institutions.

In spite of the proliferation of online course-taking, many university faculty members are reluctant to teach courses via the Internet. In the fall of 2004, 26\% of chief academic officers noted that "lack of acceptance of online instruction by faculty" is a significant barrier to the largescale implementation of online courses” (Allen \& Seaman, 2006, p. 13). As of fall 2009, only $31 \%$ of these university administrators agreed that faculty perceive online instruction as valuable and legitimate.

Interaction is a pivotal element of a powerful learning environment (Kester, Kirschner, \& Corbalan, 2006). However, "educators do not yet know what forms of interaction people need, want, or expect to support their learning; and until we fully understand what it is about face-toface interactions that enhance learning, we cannot know what features are required for an online system” (Wanstreet, 2006). It is this caveat that inspired the present study.

\section{Purpose and Description of the Study}

Examining and illuminating the perspectives of instructors and students who are involved in online courses can offer insights into the utility of various types of online instruction for graduate-level courses. The particular research focus on instructors and students using a synchronous technology with unique audio features provides insights into the medium's impact upon the concerns of instructors relative to course quality in online learning environments. Relatively little literature exists on instruction via synchronous online technologies that enable two-way audio interaction between instructor and students. The researchers describe this course delivery platform as synchronous interactive online instruction (SIOI). Using a mixedmethodology approach, the authors examined an online course medium used in graduate-level courses in educational leadership from two vantage points: 1) instructor perceptions regarding the quality of courses delivered via online instruction, and 2) student perceptions regarding the quality of courses delivered via online instruction.

\section{Theoretical Framework and Related Review of Research Literature}

While acknowledging that some instructors are reluctant to offer online courses because of entrenched approaches to instruction and/or ineptitude with instructional technologies, this study examines instructor reticence based on concerns over perceived inadequacies of online environments to attend to certain features of teaching and learning. Many instructors who are otherwise comfortable with technology in instruction cite concerns about online formats. They 
express concern over reduced human interaction, technology malfunctions, variable technology proficiencies of students, and increased faculty workload (Beard \& Harper, 2002). The authors chose to explore very specifically instances in which the resistance to online instruction was described by university professors - each of whom was comfortable and proficient with a number of computer and online applications - as a product of their concerns over the quality of teaching and learning in such venues. The researchers focused on three areas of theory that undergird conceptualizations of desirable learning environments: pedagogical orientation, social constructivism, and immediacy and interaction. The related review of research addresses primarily three types of learning environments: face-to-face instructor and student instruction; asynchronous online instruction; and synchronous instruction, including two-way audio enhanced online formats.

\section{Pedagogical Orientation}

The pedagogical orientations espoused by university instructors are pivotal as they consider the merits (or absence thereof) of online instruction. Core courses in professional schools are heavily oriented toward practitioner tasks (e.g., scenarios, simulations, practica, etc.). These are typically complex learning situations, integrating content across multiple disciplines. Such tasks promote deep learning and heighten prospects of successful transference of knowledge and skill to subsequent professional practice (Van Merriënboer, 1997). According to Newmann and Wehlage (1993), several conditions characterize authentic learning activities: analysis based upon depth of knowledge, dependence upon higher order thinking, substantive dialogue, social support for learners, and real-world applicability. Thoughtful presentation, demonstration, monitoring, and feedback positively impact student mastery of novel and complex material (Chen \& Shaw, 2006).

Van Merriënboer and Kirschner (2001) distinguished between a world of knowledge and a world of learning. "In the world of knowledge, designers construct methods by which given learning goals in a specific subject matter domain can be attained by the learner. In the world of learning, ...designers focus on methods enhancing deep level learning, intrinsic motivation, and collaborative argumentation” (p. 430). Kester, Kirschner, and Corbalan (2006) describe learning environments in which 1) complex learning occurs, 2) student motivation for learning is intrinsic, and 3) dialogue and debate are integral elements.

Various researchers have addressed the issue of quality in college-level teaching. Onwuegbuzie Witcher, Collins, Filer, Wiedmaier, and Moore (2007) found that college students believe teachers are effective when they are responsive, enthusiastic, student-centered, professional, and expert. Students further perceive their instructors to be effective when they provide multiple opportunities for student and professor interactions, impart critical information clearly and accurately, and organize the learning environment so that time is used well and the environment is orderly. Based upon some 50 years of research on college pedagogy, Chickering and Gamson (1987) developed seven dimensions of practice that have been widely accepted as criteria of quality in university instruction. An instructor is effective when he/she does the following:

- encourages student-faculty contact 
- encourages cooperation among students

- encourages active learning

- provides prompt feedback to students

- emphasizes time on task

- communicates high expectations

- respects diverse talents and ways of learning

The degree to which such dimensions of instructional effectiveness are fulfilled is impacted not only by instructor behaviors and characteristics, but also by the techniques and media through which instruction is delivered. Many instructional techniques that work well for simple tasks do not work well for complex tasks. Learners who are confronted with new and difficult material typically are not organized in their thought processes, nor is it clear to them how to prioritize and focus upon the most salient information in order to independently proceed with related learning tasks (Ormrod, 2004).

The degree to which online learning can attend to multiple dimensions of teaching and learning is of paramount interest to the instructor. While online content is more accessible, obtaining information is only one stage of gaining command over complex content. Hofer, Yu, and Pintrich (1998) found that self-regulation of learning is difficult for most students. Students in online courses often have difficulty with comprehension and application of information (Schwartzman, 2007). Oh and Jonassen (2007) assert that merely providing information to students is insufficient - the nature of discourse in asynchronous online courses (postings and threaded discussions guided by the instructor) aligns poorly with the inherent complexity of learning processes associated with mastering complex course content.

\section{Constructivism}

Driscoll (2000) describes constructivism as a theory of learning that assumes that knowledge is constructed by learners via a formative process that relies not only on what is transmitted by the medium (instructor, text, audiovisual source) but also on the manner in which the learner makes sense of content within the context of his/her existing knowledge and experiences. Social constructivism extends these notions by asserting that learning is greatly dependent upon the interactions, collaboration, and social exchanges that occur in that learning context. Woo and Reeves (2007) outline multiple criteria for learning environments consistent with these theoretical orientations: Instructors who base learning environments upon these principles will 1) engage learners in authentic learning tasks; 2) create opportunities for meaningful collaboration among the instructor, experts, and other students; 3) engage the students themselves in defining, implementing, and negotiating perspectives relative to these tasks; 4) use collaboration, debate, and analysis to refine and complete the learning tasks; and 5) assure that students have access to the instructor, resources, and one another in order to clear points of confusion and expand concepts. "Such a meaningful interaction process is required for meaning making and hence learning (Woo \& Reeves, 2007, p. 20). 
Such approaches to teaching and learning have significant implications for the nature of the classroom and related environments. The instructional applications of email, online resources, typed threaded online discussions, and interactive online audio technologies need to be very deliberately designed if they are to ensure that learning environments consistent with the principles of constructivism are provided. Such design requires "change in pedagogical thinking toward student-centered classrooms with lots of constructivist, project-based activities, with opportunities for social discourse and collaboration between teacher and student, and between student and student” (Creighton, 2003, p. xiii). The difficulty of doing these things well online is the basis for the conclusion by Woo and Reeves that "despite the obvious advantages of the Web, relatively few authentic web-based learning programs have been developed and implemented at various levels of education” (p. 21). Others assert that computers and the Internet have exponentially expanded access to authentic instructional experiences via simulation, access to information and experts, virtual access to remote locations, complex manipulations of data, and sophisticated presentation capabilities (Woo \& Reeves, 2007; Herrington et al., 2004). Comparing the capacities of face-to-face, online asynchronous, and online synchronous learning to facilitate knowledge transfer, Chen and Shaw (2006) found that for instruction sustained over substantial periods of time, there were no differences in learning outcomes among the three instructional modalities.

Various authors have studied collaboration among students in three instructional modalities: face-to-face, online synchronous, and online asynchronous sessions. Students tend to collaborate more extensively in the face-to-face and synchronous online sessions (Mabrito, 2006; Meyer, 2003). Meyer (2003) found that students believed that their contributions to asynchronous collaboration were of higher quality because of the expanded availability of time to craft and edit their postings.

The potential of web-based learning to enhance dimensions of constructivist learning approaches is significant, yet Woo and Reeves (2007) argue that the potential remains largely untapped in college classrooms. Wang and Woo (2007) found that the responsiveness of the instructor, interaction and communication between class participants, and the quality of the learning climate were lower in asynchronous online classes than in face-to-face instruction.

\section{Interaction and Engagement}

Theories of interaction and engagement are integrally connected to social constructivism. For students and instructors, interaction is an important dimension of university course work. Hirumi (2002) notes, however, that only certain dimensions of interaction are significantly related to higher achievement. Interaction that a) prompts intellectual insight, b) provokes analysis, and c) deepens commitment to instructional activities influences the quality of learning; sharing personal observations is of limited value. Savery and Duffy (1995) contend that the active engagement of students in discourse during analysis of complex problems prompts learning through comparative mental processes and enriches application of content to other problem-solving circumstances. The quality of interaction and engagement between instructor and students is related to both 
student performance and to satisfaction; so, too, is the quality of collaboration among students themselves (Chickering \& Gamson, 1987; Onwuegbuzie et al., 2007).

Perceptions of quality and level of immediacy and engagement in face-to-face and online instructions may differ. Bernard, Brauer, Abrami, and Surkes (2004) define online interaction as the ability to collaborate with peers and instructor. Wanstreet (2006) found that online interaction both between learners and between learner and instructor addresses learning-style preferences of students. The nature of interaction is, by extension, an important consideration in the design of online learning and in students' evaluations of the quality of their experiences in such courses. While a number of features of online course work lend themselves to interaction, the degree to which they fulfill student needs for interaction and immediacy can vary significantly.

Many researchers and experts laud the capacities of online media to enhance interaction and engagement. Threaded discussions, online chat, email, and, in some instances, two-way audio and video feeds expand the nature and richness of interaction. The asynchronous timing of much of this interaction also conforms better to the schedules of some students. "Technology provides an electronic learning mileux that fosters the kind of creativity and communication needed to nourish engagement” (Kearsley \& Shneiderman, 1998, p. 7). Ho and Swan (2007) note the capacity of online instruction to assure a more democratic approach to interaction because domination of the online "dialogue" by any one individual is less likely to occur. They also found that frequency, manner, and quality of contributions were positively correlated with final course grades.

Other researchers raise questions about the quality of interactions online. Wanstreet (2006) observed that research that reflects positively on online communication in college courses typically focuses more upon the quantity rather than quality. Zhang and Walls studied the degree to which online instruction addressed the previously described dimensions of instructional effectiveness developed by Chickering and Gamson. They found that the elements of "encouraging cooperation among students and encouraging student-faculty contact were least frequently practiced” in online instruction (Zhang \& Walls, 2006, p. 420). Mazzolini and Maddison (2005) noted that the frequency, timing, and nature (e.g., clarifying, posing questions, answering questions) of an instructor's contributions to online postings and threaded discussions are negatively correlated with the frequency and length of student postings.

\section{Summary}

The literature on the capacities of online instruction to address important dimensions of effective college learning environments is mixed. Of great significance to the present study was the dearth of literature addressing certain online instructional delivery systems, such as synchronous interactive online instruction. SIOI technology, which is still relatively new, provides synchronous online classrooms that are enhanced by two-way audio features that allow real-time oral presentation, discourse, and checks for understanding among instructor and students. The absence of such studies, however, makes it particularly difficult to draw conclusions about the 
capacity of this form of online learning to address key elements of instructional effectiveness and to compare these capacities to those inherent in face-to-face and online asynchronous classrooms.

\section{Methodology}

\section{Introduction}

This study examined the SIOI course medium from two vantage points: 1) instructor perceptions regarding the quality of courses delivered via online instruction, and 2) student perceptions regarding the quality of courses delivered via online instruction.

\section{Qualitative Study of Instructor Perceptions}

The qualitative component of this study addressed instructor perceptions regarding the quality of courses delivered via online instruction. Qualitative research involves an examination of what people said about their experiences, dispositions, and thoughts as they relate to a specific phenomenon. Heidegger (1962) described the phenomenological approach as "that which shows itself in itself” (p. 51). Crotty (1998) noted phenomenology is an attempt to gain an in-depth understanding of the human experience.

Specific research questions were examined within the context of the qualitative study that examined instructor perspectives regarding online courses:

Were there challenges to implementing a synchronous interactive online instructional (SIOI) format?

Was the process of social interaction in the SIOI environment productive?

Were professors able to provide a quality learning experience via SIOI format?

In the spring of 2007, the University of Southern Mississippi provided SIOI technology for professors interested in a course delivery system that employs a synchronous interactive online instructional format. The following semester, the researchers proceeded with participant selection and research processes pursuant to the phenomenological tradition. The population ( $N$ $=14$ ) for the qualitative study of instructor perceptions regarding the quality of courses delivered via online instruction included all professors teaching SIOI-enabled courses at the University of Southern Mississippi. Seven (50\%) of the faculty members responded.

Survey research was the method used for gathering data from faculty participants who were implementing SIOI technology. A structured questionnaire, which also contained opportunity for open comments, was developed. Qualitative data analysis involved identifying, coding, and categorizing patterns found in the data. 
Having coded and analyzed the data, a narrative was prepared to further disseminate research findings. The individual's interpretation of an event comprises reality for that individual (Bogdan \& Biklen, 1982). The goal of the researcher is to understand the research environment, the individuals, and their behavior. Glesne and Peshkin (1992) noted that analysis is an immediate and ongoing process of qualitative research.

\section{Quantitative Study of Student Perceptions}

Specific research questions were explored within the context of the quantitative study that examined student perceptions regarding the quality of courses delivered via online instruction:

What are students' perceptions regarding the quality of their learning experiences in synchronous interactive online instruction (SIOI)?

Are there statistically significant differences among the ratings of students regarding the degree to which course quality criteria are met through face-to-face, asynchronous online, and synchronous interactive online instruction (SIOI) course formats?

Is there a relationship between demographic characteristics of students and their perceptions regarding the quality of their learning experiences with synchronous interactive online instruction (SIOI)?

Is there a relationship between demographic characteristics of students and their perceptions of the degree to which course quality criteria are met through face-to-face, asynchronous online, and synchronous interactive online instruction (SIOI) course formats?

In the spring of 2007, the University of Southern Mississippi provided SIOI technology for professors interested in a course delivery system that employs a synchronous interactive online instructional format. The sample population for the quantitative study of student perceptions regarding the quality of courses delivered via online instruction included all students enrolled in SIOI-enabled graduate courses included in the program of studies for educational leadership at the University of Southern Mississippi during this and four subsequent semesters.

The quantitative study of student perceptions employed a survey instrument designed by the researchers and entitled Survey of Opinions of Users of SIOI. The instrument included items through which survey completers provided demographic information, assessments of their proficiencies with various computer applications, and assessments of the utility of particular utilities of the SIOI technology. A section of questions regarding overall impressions regarding this medium was included. Numerous authors have, over time, assembled models that outline criteria to assess the quality of teaching and learning in university courses. Chickering and Gamson's (1987) dimensions of effective college instruction were adapted to provide a section in which students compared the capacities of face-to-face delivery, SIOI, asynchronous online 
instruction, and other online modes of course delivery. Data were analyzed using descriptive, differential, and correlational statistical techniques.

\section{Results}

\section{Qualitative Study of Instructor Perceptions}

Relatively few instructors at the University of Southern Mississippi in 2007 delivered courses via synchronous interactive online instruction (SIOI). Of the 14 using this platform at the time of this study, seven (50\%) participated. Users and respondents were broken down as follows: College of Education and Psychology - 6 users, of whom 5 responded; College of Science and Technology 7 users, of whom 1 responded; College of Business - 1 user, who also responded. In light of this relatively small number, the researchers view the data from this portion of the study to be a work in progress. That said, early analysis of results yielded findings of interest.

Research Question 1: Were there challenges in implementing a synchronous interactive online instructional (SIOI) format?

Table 1

Challenges Confirmed and Identified by Respondents

\begin{tabular}{|l|c|c|c|c|c|c|}
\hline Question 1 & $\begin{array}{c}(5) \\
\text { Strongly } \\
\text { agree }\end{array}$ & $\begin{array}{c}(4) \\
\text { Agree }\end{array}$ & $\begin{array}{c}(3) \\
\text { Neutral }\end{array}$ & $\begin{array}{c}(2) \\
\text { Disagree }\end{array}$ & $\begin{array}{c}(1) \\
\text { Strongly } \\
\text { disagree }\end{array}$ & (NA) \\
\hline $\begin{array}{l}\text { Implementing a synchronous } \\
\text { interactive on-line instructional } \\
\text { format (SIOI) presented certain } \\
\text { challenges. }\end{array}$ & $\begin{array}{c}n=3 \\
43 \%\end{array}$ & $\begin{array}{c}n=2 \\
29 \%\end{array}$ & 0 & $\begin{array}{c}n=1 \\
14 \%\end{array}$ & 0 & $n=1$ \\
\hline
\end{tabular}

Five respondents (72\%) agreed or strongly agreed there were significant challenges associated with the implementation of SIOI. Challenges identified by professors in this study were threefold. Technical issues, mastery of the SIOI collaborative operating system, and, lastly, the necessary time commitment related to planning and preparation were identified.

Technical issues included but were not limited to audio difficulties, Internet access and connectivity issues, log-on problems, and WebCT inaccessibility. Learning and then practicing to become proficient with all the "bells and whistles of this medium" presented a different set of challenges for respondents. One professor noted, "It takes time for the use of the console to become second-nature." SIOI requires a continuous technology focus and therefore, “... trying to teach and troubleshoot technology problems was also quite challenging." The fact that everything happens in real time is another consideration. Lastly, one respondent admonished, “...plan well ahead of time to insure content, pedagogy, and technology goals are met...the time commitment is quite high in terms of getting the students and presenters ready for a problem-free live classroom session.” 
Research Question 2: Was the process of social interaction in the SIOI environment productive?

Table 2

The Nature of Social Interaction in SIOI

\begin{tabular}{|l|c|c|c|c|c|c|}
\hline \multicolumn{1}{|c|}{ Question 2 } & $\begin{array}{c}(5) \\
\text { Strongly } \\
\text { agree }\end{array}$ & $\begin{array}{c}(4) \\
\text { Agree }\end{array}$ & $\begin{array}{c}(3) \\
\text { Neutral }\end{array}$ & $\begin{array}{c}(2) \\
\text { Disagree }\end{array}$ & $\begin{array}{c}\text { (1) } \\
\text { Strongly } \\
\text { disagree }\end{array}$ & (NA) \\
\hline $\begin{array}{l}\text { Social interaction between } \\
\text { instructor/ students and } \\
\text { student/students was a meaningful } \\
\text { and productive process in the SIOI } \\
\text { experience. }\end{array}$ & $\begin{array}{c}n=2 \\
29 \%\end{array}$ & $\begin{array}{c}n=4 \\
57 \%\end{array}$ & 0 & 0 & 0 & $n=1$ \\
& & & & & & \\
\hline
\end{tabular}

Six respondents (86\%) agreed or strongly agreed social interaction between instructor/students and student/students was a meaningful and productive process in the SIOI experience. Respondents indicated social interaction can be enhanced by using multiple console features such as "chat box...online polling...email...telephone outside of class...meeting in groups...meet and greets prior to class... and breakout rooms for some class activities." This category emphasizes utilization of tools within SIOI to accentuate the social interaction process.

A second area of interest was the students' and professors' purpose for social interaction within the synchronous interactive online instructional format. Collaboration is viewed by the researchers as a dimension of the process of social interaction. As one respondent noted, "If the social interaction fails to be meaningful then the process will soon become unproductive." Adding emphasis to this point, another respondent observed, "As with learning communities themselves, students return again and again to valuable information sources....to the extent that collaboration is meeting the needs of the learner it is a valuable student-centered entity." Advancing this perspective on the role of "purpose" in social interaction, another respondent concluded, "The success of live classroom [SIOI] is more dependent on the facilitation and frontend work by the instructor." However, one respondent advanced the concept that students seek to find a purpose through identity; he noted, "During this [social interaction] process they [students] struggle to forge an identity in the new online environment.

Research Question 3: Were professors able to provide a quality learning experience via SIOI format? 
Table 3

Respondents' Comments on Quality Learning

\begin{tabular}{|l|c|c|c|c|c|c|}
\hline Question 3 & $\begin{array}{c}(5) \\
\text { Strongly } \\
\text { agree }\end{array}$ & $\begin{array}{c}(4) \\
\text { Agree }\end{array}$ & $\begin{array}{c}(3) \\
\text { Neutral }\end{array}$ & $\begin{array}{c}(2) \\
\text { Disagree }\end{array}$ & $\begin{array}{c}(1) \\
\text { Strongly } \\
\text { disagree }\end{array}$ & (NA) \\
\hline $\begin{array}{l}\text { The instruction offered through } \\
\text { SIOI provided a quality } \\
\text { learning experience for } \\
\text { students. }\end{array}$ & $\begin{array}{c}n=3 \\
43 \%\end{array}$ & $\begin{array}{c}n=3 \\
43 \%\end{array}$ & 0 & 0 & 0 & $n=1$ \\
\hline
\end{tabular}

Positive student evaluations [ratings] were mentioned by some respondents as evidence of a quality learning experience. One respondent noted, "I base this seemingly self-congratulatory rating on the anonymous ratings of students." Another shared, "Live classroom was rated by students as the most beneficial aspect of the course offering." Student opinion with regard to quality learning was an important factor for professors. Several respondents were aware of student perceptions; one declared, "Based on previous student feedback, many felt that 3-4 live classroom sessions is all that is desired."

There is a solemn warning as one respondent observed, "The SIOI application is often criticized because of frequent technological lapses... a negative image tends to label the learning experience as unreliable, burdensome and unproductive.” The implication was that frequent user problems will brand the SIOI technology unfairly. Still another respondent offered a conditional perspective; he noted, "The quality learning experience seems directly proportionate to the institution's commitment to service and support.”

Two respondents qualified their responses when commenting on whether SIOI provided a quality learning experience. The first responded, "The verdict is still out because I have two different experiences as I have presented.” Again, the respondent is referencing frequent technological problems as a matter of concern. The other respondent in this category acknowledged a good evaluation but concluded, "I know we can get better-and will!"

Six respondents (86\%) agreed or strongly agreed that the instruction offered through SIOI provided a quality learning experience for students. In summary, the professors as respondents indicated student evaluations, problem-free online sessions, and continuous service/support from the university were determinants in the quality learning process.

A final question was posed to respondents. Instructors were asked whether, as a result of using SIOI, they were likely to continue to offer courses in this instructional format. Five of the respondents (72\%) indicated that they were more likely to offer courses online because of this instructional format. One indicated that SIOI had no impact on the willingness to offer courses online. None of the respondents indicated that they were less likely to offer courses online. 
Table 4

Respondents' Inclination toward Future Use of SIOI Format

\begin{tabular}{|c|c|c|c|c|}
\hline Question & $\begin{array}{c}\text { (1) } \\
\text { I am more } \\
\text { likely to offer } \\
\text { online courses } \\
\text { because of this } \\
\text { instructional } \\
\text { platform. }\end{array}$ & $\begin{array}{c}(2) \\
\text { This } \\
\text { instructional } \\
\text { platform has not } \\
\text { affected my } \\
\text { willingness to } \\
\text { offer online } \\
\text { courses. }\end{array}$ & $\begin{array}{c}\text { (3) } \\
\text { I am less } \\
\text { likely to } \\
\text { offer online } \\
\text { courses } \\
\text { because of } \\
\text { this } \\
\text { instructional } \\
\text { platform. }\end{array}$ & $\begin{array}{c}\text { Other (please construct } \\
\text { your own response): }\end{array}$ \\
\hline $\begin{array}{c}\text { SIOI affected } \\
\text { my attitude } \\
\text { toward online } \\
\text { course delivery } \\
\text { in the following } \\
\text { manner: }\end{array}$ & $n=5$ & $n=1$ & 0 & $n=1$ \\
$14 \%$ & $14 \%$ & $14 \%$ \\
\hline
\end{tabular}

\section{Quantitative Study of Student Perceptions}

The Survey of Opinions of Users of SIOI was administered to all students enrolled in SIOIenabled graduate courses included in the graduate program of studies for educational leadership at the University of Southern Mississippi. Surveys were administered to 124 students, and 95 completed the instruments, thus providing a response rate of $77 \%$.

The survey instrument administered to students in SIOI-enabled classes included questions regarding demographic descriptors of the participants. Among the 93 respondents reporting age, ages ranged from $24-60$ years, with the majority $(n=45)$ falling between 30 and 39 years. Twenty-nine students were between 40 and 49 years. Eleven participants were younger than 30 years and eight were 50 years and older. The mean age was 37.84 years.

Females comprised nearly two-thirds of the sample $(61.1 \%, n=58)$; whereas, males made up $38.9 \%(n=37)$. Among those reporting professional role, respondents included teachers $(68.9 \%$, $n=62)$, administrators $(20 \%, n=18)$, and 'other' $(11.1 \%, n=10)$.

Research Question 1 was stated as follows: “What are students’ perceptions regarding the quality of their learning experiences in synchronous interactive online instruction (SIOI)?” Question 14 on the survey was stated as follows: "On a scale of 1 to 5 , with 1 being the lowest rating and 5 being highest, what rating would you give to your overall experience with SIOI in this course?” Table 5 illustrates both the mean and the frequencies associated with each rating. 
Table 5

Mean and Frequencies of Ratings of Overall Experience with SIOI

\begin{tabular}{|c|c|c|}
\hline & $N$ & Mean \\
\hline Mean of participants' ratings & 92 & 4.24 \\
\hline \multicolumn{2}{|l|}{ Frequencies } & \\
\hline Rating 1 (lowest rating) & 0 & \\
\hline Rating 2 & 3 & \\
\hline Rating 3 & 9 & \\
\hline Rating 4 & 43 & \\
\hline Rating 5 (highest rating) & 37 & \\
\hline
\end{tabular}

Research Question 2 was stated as follows: "Are there statistically significant differences among the ratings of students regarding the degree to which course quality criteria are met through faceto-face, asynchronous online, and synchronous interactive online instruction (SIOI) course formats? The pertinent item (Item 17) of the survey instrument was stated as follows:

Using the criteria in the table below, rate the dimensions of instructional effectiveness in courses delivered in the following formats:

- SIOI

- Asynchronous online format

- Face-to-face

- Other distance delivery format (e.g., closed circuit video link connecting instructor/ classroom).

The scale used is 1 to 5 , with 1 being the lowest rating and 5 being highest.

The mean student rating for the quality of each course format relative to each dimension of instructional effectiveness is provided in the related column of Table 6. Because of the nature of the wording of the questionnaire items to align with Chickering and Gamson's seven principles, it was not possible to determine a summary rating for each of the three class formats and make a direct overall comparison. However, in comparing each of the dimensions across the three formats, several differences were suggested. ANOVA's were employed to discern these differences among ratings of each dimension of instructional effectiveness among the SIOI, asynchronous online, and face-to-face modes of delivery.

Student ratings for the following dimensions of instructional effectiveness were not significantly different when contrasting face-to-face and SIOI formats; however, the ratings for both face-to- 
face and SIOI formats were significantly higher than the ratings for asynchronous online learning $(p<.001)$ :

- encouraged student-faculty contact

- encouraged cooperation among students

- encouraged active learning

- provided prompt feedback to students

- emphasized on time on task

- communicated high expectations

- respected diverse talents and ways of learning.

Three dimensions of instructional effectiveness in courses taken were added by the authors to those developed by Chickering and Gamson (1987). Students were asked to rate the quality and amount of content learned across the three instructional formats. There were significant differences in the perceptions of quality of learning when comparing different formats $(p<.001)$. While SIOI $(M=4.71)$ and face-to-face $(M=4.73)$ formats were not different from each other, both were rated higher than the asynchronous format $(M=3.96)$. Student ratings for the degree to which the SIOI format assured ease of access to the course were not significantly higher than the ratings for the asynchronous online learning format. The ratings for both were significantly higher than the ratings for the face-to-face format in this quality dimension $(p=.023)$. Student ratings for the degree to which the various formats minimized costs (other than tuition) of taking the course were not significantly different for SIOI and asynchronous formats, but both were significantly higher than face-to-face format $(p=.034)$. 
Table 6

Mean Student Ratings of the Quality of Course Formats Relative to Dimensions of Effective College Instruction

\begin{tabular}{|l|c|c|c|c|c|c|}
\hline \multicolumn{1}{|c|}{ Dimensions } & $\begin{array}{c}\text { SIOI format } \\
\text { (SIOI) } \\
\text { Mean, SD }\end{array}$ & $\begin{array}{c}\text { Min } \\
-\end{array}$ & $\begin{array}{c}\text { Asynchronous } \\
\text { online format } \\
\text { Mean, SD }\end{array}$ & $\begin{array}{c}\text { Min } \\
\text { Max }\end{array}$ & $\begin{array}{c}\text { Face-to- } \\
\text { face format }\end{array}$ & $\begin{array}{c}\text { Min } \\
\text { Max }\end{array}$ \\
\hline $\begin{array}{l}\text { The quality and the } \\
\text { amount of the } \\
\text { content learned }\end{array}$ & $4.71(.622)$ & $2-5$ & $3.96(.735)$ & $3-5$ & $4.73(.450)$ & $4-5$ \\
\hline $\begin{array}{l}\text { Encouraging student- } \\
\text { faculty contact }\end{array}$ & $4.34(.814)$ & $2-5$ & $2.84(1.09)$ & $1-5$ & $4.67(.596)$ & $3-5$ \\
\hline $\begin{array}{l}\text { Encouraging } \\
\text { cooperation among } \\
\text { students }\end{array}$ & $4.04(1.26)$ & $1-5$ & $2.69(1.14)$ & $1-5$ & $4.38(.979)$ & $1-5$ \\
\hline $\begin{array}{l}\text { Encouraging active } \\
\text { learning }\end{array}$ & $4.29(.991)$ & $1-5$ & $3.01(1.02)$ & $1-5$ & $4.40(.904)$ & $1-5$ \\
\hline $\begin{array}{l}\text { Providing prompt } \\
\text { feedback to students }\end{array}$ & $4.41(.825)$ & $2-5$ & $2.89(1.02)$ & $1-5$ & $4.48(.690)$ & $3-5$ \\
\hline $\begin{array}{l}\text { Emphasizing time on } \\
\text { task }\end{array}$ & $4.21(1.13)$ & $1-5$ & $3.05(1.28)$ & $1-5$ & $4.31(.924)$ & $1-5$ \\
\hline $\begin{array}{l}\text { Communicating High } \\
\text { Expectations }\end{array}$ & $4.45(.932)$ & $1-5$ & $3.26(1.24)$ & $1-5$ & $4.54(.645)$ & $3-5$ \\
\hline $\begin{array}{l}\text { Respecting diverse } \\
\text { talents and ways of } \\
\text { learning }\end{array}$ & $3.97(1.16)$ & $1-5$ & $2.94(1.25)$ & $1-5$ & $4.26(1.02)$ & $1-5$ \\
\hline $\begin{array}{l}\text { Ease of access to the } \\
\text { course }\end{array}$ & $4.39(1.04)$ & $1-5$ & $4.09(1.23)$ & $1-5$ & $3.70(1.07)$ & $1-5$ \\
\hline $\begin{array}{l}\text { Minimizing costs } \\
\text { taking course }\end{array}$ & $3.97(1.27)$ & $1-5$ & $3.68(1.31)$ & $1-5$ & $3.57(1.22)$ & $1-5$ \\
\hline
\end{tabular}

Research Question 3 was stated as follows: "Is there a relationship between demographic characteristics of students and their perceptions regarding the quality of their learning experiences with synchronous interactive online instruction (SIOI)?” Items $14-16$ on the survey read as follows:

14. On a scale of 1 to 5 , with 1 being the lowest rating and 5 being highest, what rating would you give to your overall experience with SIOI in this course? 
15. Would you take another course via SIOI? (Yes, No, Maybe)

16. Would you recommend a course taught via SIOI to others?

(Yes, No, Maybe)

The mean rating for overall experience with the SIOI format (item 14) was 4.24 on a 5-point scale. In response to item 15, "Would you take another course via SIOI?," seventy-five (85.2\%) answered "yes," ten (11.4\%) said "maybe," and three respondents (3.4\%) said "no." When asked whether they would recommend a course taught via SIOI to others (item 16), 84.5\% responded "yes," $12.8 \%$ responded "maybe," and 2.6\% said "no." Chi-square analyses were employed to evaluate relationships among gender or professional role and the responses to items 14, 15, and 16. No significant relationships were discerned. While not statistically significant $(p=.051)$, there is some indication that the reported overall experience with SIOI format is negatively related to the age of the respondent.

Research Question 4 was stated as follows: Is there a relationship between demographic characteristics of students and their perceptions of the degree to which course quality criteria are met through face-to-face, asynchronous online, and synchronous interactive online instruction (SIOI) course formats? Chi-square analyses were employed to evaluate relationships among professional role and the responses to the items addressing dimensions of instructional effectiveness, which are profiled in Table 6. No significant relationships were found with the exception that teachers, less so than administrators, reported that the asynchronous format respects diverse talents and ways of learning. In comparing gender ratings for SIOI, asynchronous, and face-to-face dimensions, there were no differences for the asynchronous

dimensions. Females rated the quality and amount of content learned somewhat higher than males (females, $M=4.81$; males, $M=4.67$ ) for the SIOI, as well as for face-to-face course formats, though the differences were not significant. Females did, however, rate quality and amount of content learned significantly higher than males for asynchronous format courses. Females also rated the respecting of diverse talents and ways of learning higher in the SIOI format than did the males. T-test analyses further revealed gender differences in student perceptions of several dimensions of instructional effectiveness when face-to-face instruction is used. The ratings of women concerning the degree to which the face-to-face format encouraged both cooperation among students and active learning as well as assured the provision of prompt feedback to students, emphasis on time on task, and the communication of high expectations were significantly higher than the ratings given by men for these same dimensions of instructional quality $(p<.05)$.

\section{Discussion and Conclusions}

Many university instructors question whether the quality of learning achieved by students in a face-to-face environment can be paralleled in an online format, especially for novel and complex content. This study examined instructor perceptions of the merits of synchronous interactive online instruction (SIOI). Student respondents provided perspectives on the relative capacities of 
face-to-face, SIOI, and asynchronous online learning to address dimensions of instructional effectiveness. Although corrections were used for the alpha levels before reporting significant differences among student ratings, these results should nonetheless be interpreted with some caution due to the large number of analyses employed. Additional caution is warranted in light of the relatively small number of participants and the fact that they were enrolled in a single professional discipline, educational leadership. Finally, a distinction needs to be drawn between perceptions of the quality of instruction/learning and the actual measurement of the quality of instruction/learning. This study addressed the former.

The analysis of responses suggests that while the format presents challenges, instructors view SIOI favorably. These respondents evaluated the quality of learning in these classes positively, and were, in general, pleased with the nature of student-to-instructor and student-to-student interaction in these classes. Given the literature's frequent references to the premium that instructors attach to these dimensions of learning, these findings are instructive, particularly to faculty members who are disinclined to offer instruction online.

Students also gave positive ratings to the overall quality of the learning experience in SIOIenabled courses. A significant majority indicated that they would be willing to take another course offered in the SIOI medium, and a similar majority was willing to recommend the SIOI format to other students.

Based on dimensions of instructional effectiveness, students compared SIOI-enabled courses to those offered face-to-face and in an asynchronous online format. While the ratings of the amount and quality of content learned were the same for SIOI and face-to-face course formats, mean student ratings for the dimensions of instructional quality tended to be slightly higher for face-toface instruction than for SIOI; these differences, however, were not statistically significant. These findings are important as they suggest to an instructor who is reluctant to employ online learning that students perceive that it is possible to achieve levels of effectiveness in an online instructional format similar to those that are realized in face-to-face delivery.

Asynchronous online learning, on the other hand, was perceived to be inferior to both face-to-face and SIOI formats in addressing dimensions of instructional quality. Mean ratings by students of the capabilities of asynchronous online learning to address these dimensions were consistently and significantly lower than the ratings for both face-to-face and the SIOI formats. These findings will likely reinforce the reluctance of some instructors to offer online instruction if the only option for delivery is an asynchronous format. As Barnes (2003) observes, "The online format must assist in making information more understandable and relevant to students.”

Two additional dimensions of quality, ease of access and minimizing costs (other than tuition) of taking the course, were rated by students as being significantly higher for the two online formats than for the face-to-face format. In an era of escalating fuel prices, recessionary economic trends, and increasing awareness of access to online instructional opportunities, these are not surprising findings for course offerings that typically allow students access from home. 
While not statistically significant, there is evidence of some concern relative to the quality of student collaboration in SIOI-enable courses. The ratings for this dimension, as well as the dimension of student-faculty contact, were significantly lower for the asynchronous mode. These concerns are more significant when the results are analyzed by gender. The challenge to online faculty is obvious - for these important elements of instructional effectiveness to be adequately addressed, instructors will need to capitalize on those mechanisms for interaction and collaboration that are available.

Future study is warranted. As the use of synchronous interactive online learning expands in postsecondary instruction, it will be useful to survey additional instructors and students participating in SIOI-enabled courses. "The bottom line is that to increase the learning effects of online interaction, we should, first of all, understand clearly the nature of interaction within the framework of social constructivist learning theory. Once we gain such an in-depth understanding, we should be able to engage in productive research and development to identify the necessary design principles for implementing more effective interaction activities within Web-based learning environments” (Woo \& Reeves, 2007, p.23). 


\section{References}

Allen, E., \& Seaman, J. (2010). Learning on demand: Online education in the United States, 2009. Needham, Mass.: Sloan-C.

Allen, E., \& Seaman, J. (2006). Making the grade: Online education in the United States, 2006. Needham, Mass.: Sloan-C.

Barnes, S. (2003). Computer-mediated communication: Human-to-human communication across the internet. Boston: Allyn \& Bacon.

Beard, L., \& Harper, C. (2002). Student perceptions of online versus on campus instruction. Education, 122(4), 658-663.

Bernard, R., Brauer, A., Abrami, P. C., \& Surkes, M. (2004). The development of a questionnaire for predicting online learning achievement. Distance Education, 25(1), 31-47.

Bogdan, R., \& Biklen, S. (1982). Qualitative research for education: An introduction to theory and methods. Boston: Allyn and Bacon.

Chen, C., \& Shaw, R. (2006). Online synchronous vs. asynchronous software training through the behavioral modeling approach: A longitudinal field experiment. International Journal of Distance Education Technologies, 4(4), 88-102.

Chenail, R. J. (1995). Presenting qualitative data. The Qualitative Report. Retrieved from http://www.nova.edu/ssss/QR/QR2-3/presenting.html.

Chickering, A. W., \& Gamson, Z. F. (1987). Seven principles for good practice in undergraduate education. AAHE Bulletin, 39(7), 3-7.

Coffey, A., \& Atkinson, P. (1996). Concepts and coding. In A. Coffey \& P. Atkinson, Making sense of qualitative data. Thousand Oaks, CA: Sage.

Creighton, T. (2003). The principal as technology leader. Thousand Oaks, CA: Corwin Press.

Crotty, M. (1998). The foundations of social research: Meanings and perspective in the research process. Thousand Oaks, CA: Sage Publications

Driscoll, M. P. (1994). Psychology of learning for instruction. Needham Heights, MA: Allyn \& Bacon.

Easton, S. (2003). Clarifying the instructor's role in online distance learning. Communication Education, 52(2), 87-105. 
Glesne, C., \& Peshkin, A. (1992). Becoming qualitative researchers: An introduction. New York: Longman.

Heidegger, M. (1962). Being and time. New York: Harper \& Row Publishers.

Hirumi, A. (2002). The design and sequencing of E-learning interactions: A grounded approach. International Journal on E-learning, 1(1), 19-27.

Ho, C. \& Swan, K. (2007). Evaluating online conversation in an asynchronous learning environment: An application of Grice's cooperative principle. The Internet and Higher Education, 10(1), 3-14.

Hofer, B., Yu, S., \& Pintrich, P. (2004). Teaching college students to be self-regulated learners. In D. Schunk \& B. Zimmerman (Eds.), Self-regulated learners: From teaching to selfreflective practice (pp. 57-85). New York: Guilford.

Kearsley, G., \& Shneiderman, B. (1998). Engagement theory: A framework for technology-based teaching and learning. Educational Technology, 38(5), 20-23.

Kester, L., Kirschner, P., \& Corbalan, G. (2006). Designing support to facilitate learning in powerful electronic learning environments, Computers in Human Behavior, 23(3), 10471054.

Mabrito, M. (2006). A study of synchronous versus asynchronous collaboration in an online business writing class. The American Journal of Distance Education, 20(2), 93-107.

Mazzolini, M., \& Maddison, S. (2005). When to jump in: The role of the instructor in online discussion forums. Computers and Education, 49(2), 193-213.

Meyer, K. A. 2003. Face-to-face versus threaded discussions: The role of time and higher-order thinking. Journal of Asynchronous Learning Networks, 7(3), 55-65.

Newmann, F., \& Wehlage, G. (1993). Five standards of authentic instruction. Educational Leadership, 55(2), 72-75.

Oh, S., \& Jonassen, D. (2007). Scaffolding online argumentation during problem solving. Journal of Computer Assisted Learning, 23(2), 95-110.

Ormrod, J. (2004). Human Learning (4th ed.). Upper Saddle River, NJ: Pearson Education.

Onwuegbuzie, A., Witcher, A., Collins, K., Filer, J., Wiedmaier, C., Moore, C. (2007). Students’ perceptions of characteristics of effective college teachers: A validity study of a teaching evaluation form using a mixed-methods analysis. American Educational Research Journal, 44(1), 113-160. 
Patton, M.Q. (1990). Qualitative evaluation and research methods (2nd ed.). Newbury Park, CA: Sage Publications.

Savery, J., \& Duffy, T. Problem based learning: an instructional model and its constructivistic framework. Educational Technology, 35, 31-38.

Schwartzman, R. (2007). Electronifying oral communication: Refining the conceptual framework for online instruction. College Student Journal, 41(1), 37-49.

Van Merriënboer, J. (1997). Training complex cognitive skills: A four-component instructional design model for technical training. Englewood Cliffs, NJ: Educational Technology Publications.

Van Merriënboer, J., \& Kirschner, P. (2001). Three worlds of instructional design: state of the art and future directions. Instructional Science, 29(4-5), 429-441.

Wanstreet, C. (2006). Interaction in online learning environments: A review of the literature. The Quarterly Review of Distance Education, 7(4), 399-411.

Wang, Q., \& Woo, H. (2007). Comparing asynchronous online discussions and face-to-face discussions in a classroom setting. British Journal of Educational Technology, 38(2), 272-286.

Woo, Y., \& Reeves, T. (2007). Meaningful interaction in web-based learning: A social constructivist interpretation. The Internet and Higher Education, 10(1), 15-25.

Zhang, J., \& Walls, R. (2006). Instructors' self-perceived pedagogical principle implementation in the online environment. The Quarterly Review of Distance Education, 7(4), 413-426.

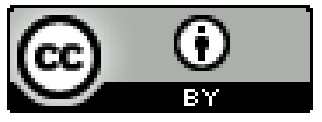

